\title{
DOCILIDADE DOS CORPOS? HORIZONTES DE UMA EXPERIÊNCIA ETNOGRÁFICA
}

\author{
Maria Larisse Elias da Silva, Universidade Federal de Campina Grande, Centro de Formação \\ de Professores - UFCG/CFP, \\ larisse_elias@hotmail.com
}

\begin{abstract}
RESUMO
Esse artigo se propõe a descortinar uma experiência obtida no Estágio Supervisionado I do curso de História - UFCG/CFP, buscando chamar atenção para necessidade de um olhar voltado para a docilidade que tem sido exercida sobre o sujeito no espaço escolar. Destarte, tomamos como objetivo compreender quais implicações esse processo de disciplinarização tem gerado nos jovens do ensino básico partindo de um relato de experiência etnográfica de estágio.
\end{abstract}

PALAVRAS-CHAVE: Docilidade dos corpos; Espaço escolar; Experiência de estágio.

\section{DOCILITY OF BODIES? HORIZONS OF AN EXPERIENCE ETHNOGRAPHIC}

\begin{abstract}
This article proposes to uncover an experience obtained in the Supervised Internship I of the History course - UFCG / CFP, seeking to draw attention to the need for a look at the docility that has been exercised over the subject in the school space. Thus, we aim to understand what implications this process of disciplinarization has generated in the youngsters of elementary education starting from a report of ethnographic experience of internship.
\end{abstract}

KEYWORDS: Docility of bodies; School space; Internship experience. 


\title{
DOCILIDAD DE LOS CUERPOS? HORIZONTES DE UNA EXPERIENCIA ETNOGRÁFICA
}

\begin{abstract}
RESUMEN
Este artículo se propone a descortinar una experiencia obtenida en la Etapa Supervisionada I del curso de Historia - UFCG / CFP, buscando llamar la atención sobre la necesidad de una mirada hacia la docilidad que se ha ejercido sobre el sujeto en el espacio escolar. De este modo, tomamos como objetivo comprender cuáles implicaciones ese proceso de disciplinarización ha generado en los jóvenes de la enseñanza básica partiendo de un relato de experiencia etnográfica de pasantías.
\end{abstract}

PALABRAS CLAVES: Docilidad de los cuerpos; Espacio escolar; Experiencia de práctica.

\section{APONTAMENTOS INICIAIS}

A docilidade dos corpos é algo que vem acompanhando o homem desde seus primeiros passos em direção à natureza que compõe o meio social. Selecionar regras que moldem o sujeito ao longo de sua vida parece essencial quando pretendemos pensar a vida em sociedade. De acordo com Michel Foucault:

Houve, durante a época clássica, uma descoberta do corpo como objeto e alvo de poder. Encontraríamos facilmente sinais dessa grande atenção dedicada então ao corpo - ao corpo que se manipula, se modela, se treina, que obedece, responde, se torna hábil ou cujas forças se multiplicam. (FOUCAULT, 1977, p. 117)

No decorrer dos séculos, vários campos do saber como a historiografia, sociologia e antropologia vem nos mostrando de que maneira essas regras para a vivência do indivíduo em sociedade tem se modificado. Desde costumes do cotidiano, como os modos de pegar os talheres, maneira de sentar-se, como se portar em lugares públicos; até costumes que designavam empoderamento, como o uso de salto alto por monarcas.

Essas modelações de como os corpos se portam não estavam presentes somente nesses momentos de convívio social, mas em todos os sistemas de controle e moldes possíveis. 
Pensar o corpo e suas performances era objetivo principal das políticas de organização social - uma organização que Foucault (1977, p. 118) vem chamar de "proibições e obrigações".

Pensando na consolidação dessa estrutura organizacional da transformação e aperfeiçoamento dos corpos, foi designado a algumas instituições a missão de educar esses sujeitos para que pudessem se perceber como indivíduos sociáveis. Nesse processo, a escola teve e tem esse papel fundamental - principalmente quando pensamos em âmbito de Brasil. Foucault (1977, p 119) aponta que podemos visualizar essas características dos moldes do poder do corpo em "escolas do exército e as escolas técnicas ou os colégios e liceus".

Sendo a escola uma instituição que trabalha a docilidade dos corpos, o controle das forças e de cada ação do corpo - como podemos perceber a apropriação dos corpos na educação básica atualmente? De que forma essa docilidade deixa lacunas no processo de ensino-aprendizagem? Qual o papel dos licenciandos diante dessa realidade?

Entendendo que essa é uma realidade presente no meio educacional, seja a nível básico ou superior, assim, tomamos como objetivo compreender quais as implicações esse processo de disciplinarização dos corpos tem gerado nas crianças de ensino básico e nos jovens universitários, a partir de uma experiência de estágio supervisionado numa escola de Ensino Fundamental da cidade de Cajazeiras-PB. Para tanto, como recurso metodológico faremos uma análise de um relato de experiência na disciplina de Estágio Supervisionado I de uma licencianda do curso de História da Universidade Federal de Campina Grande, Campus Cajazeiras - UFCG/CFP. Para que possamos utilizar de trechos do diário de bordo analisado, referenciaremos com o nome da autora do diário os trechos utilizados.

\section{A DOCILIDADE DOS CORPOS E O ESPAÇO ESCOLAR}

O espaço escolar tem sido o mais procurado no mundo contemporâneo para educar as crianças e os jovens. Muitas vezes a visão que é posta sobre a escola é aquela que vai "livrar" o sujeito dos males que as cidades podem oferecer, como a exemplo, a influência a "más" condutas. Assim, dia após dia a escola tem se tornado um campo de vigilância do sujeito, onde é apresentado uma série de regras e o jovem deve seguí-las sem "sair dos trilhos". 
Logo, a disciplina dos corpos é um dos fatores que mais influenciam no processo de ensino-aprendizagem e sociabilidade dos sujeitos escolares - de forma muitas vezes negativa. Tem se pensado num ideal de indivíduo que se adéque a um leque de regras e que a partir disso venha corresponder os objetivos que a escola elenca, sendo que esses objetivos vem sendo delineados pela sociedade. Sendo a escola ainda hoje concebida como principal instituição formadora dos sujeitos, compreender de que maneira ela pensa e dinamiza esse processo de docilidade dos corpos é essencial para que possamos descortinar novas metodologias educacionais que auxiliem os sujeitos escolares no processo de ensinoaprendizagem.

Partilhando de reflexões da filósofa Viviane Mosé (2013), somos levados a compreender o quanto a dinâmica estrutural que regimenta o espaço escolar nos conduz a uma docilidade dos corpos, pois "as escolas em sua maioria são cheias de grandes, quando não as portas são trancadas; a organização das cadeiras nas salas de aula são em fileiras, nos posicionando a ordem; o conteúdo é dividido por disciplina" - levando-nos a compreender que estamos inseridos numa docilidade até mesmo involuntária. Quando pensamos nessa docilidade involuntária, vale ressaltar que esse controle não se dá só fisicamente, mas existem outras nuances que são envolvidas nesse processo de regulamento das pequenas ações e pensamentos do sujeito.

Com isso, esse trabalho - que corresponde ao Estágio Supervisionado I do curso de História da Universidade Federal de Campina Grande, Campus Cajazeiras - se dedica a compreender o espaço escolar a partir de suas micro-impressões externalizadas no cotidiano dessa escola que recebe a estagiária. Por isso, para que possamos descortinar alguns desses fragmentos do cotidiano escolar, nos atemos a uma observação etnográfica participante. Onde pudemos estar em contato com o espaço e os sujeitos escolares semanalmente, buscando compreender como se dá a construção desse processo de docilidade dos corpos e qual ação dos jovens frente essa dinâmica escolar.

\section{A EXPERIÊNCIA ETNOGRÁFICA}

Pensando nessas nuances, voltamos nossa atenção a partir de agora para o campo em que o relato de estágio vem nos possibilitar a análise. No momento do intervalo da escola é 
possível compreender, a partir do relato de estágio que os alunos - embora inseridos nessa estrutura de regulamentação das posturas dos corpos - encontram maneiras de burlar as regras que compõe aquele cotidiano e passamos a ouvir alguns barulhos "bráxz, bráxz, bráxz!" e são os alunos, eufóricos, saindo para o recreio. Segundo Maria Larisse Elias da Silva (2017, p. 4) esse barulho se dá quando eles saem das salas "pulando em cima da grade que protege o córrego de água que tem perto da cozinha. Eles pulam incessantemente. Uns começam a comer, outros a correr, alguns se aproximam de mim e saem, até que eu decido me sentar".

Essa postura dos alunos mostra que embora eles estejam sendo observados, tendo seu tempo de alimentação e recreação cronometrado, eles "fogem pela tangente" de todo esse contingente de adestramento de suas práticas a partir das coisas que muitas vezes são percebidas como irrelevantes ao seio escolar, como as grades. O "pular nas grades" é uma representação simbólica do protagonismo ativo dos adolescentes diante da liberdade que das grades das salas de aula os priva. Essa é a maneira como eles se apropriam do espaço escolar a partir de sua carga cultural. Pierre Bourdieu discute em seu texto 'A Escola conserva: as desigualdades frente à escola e à cultura' questões que delineiam essa ideia de 'carga' ou 'capital' cultural, mas, nos apropriaremos desse diálogo mais a frente.

Assim como esse ato de resistência à docilidade, encontramos também no decorrer dessa expedição etnográfica, de acordo com Silva (2017, p. 6) "alunos do Ensino Fundamental I chegando até as grades que ficam nas portas das salas para chamar atenção" - mostrando mesmo que involuntariamente, que a necessidade que eles sentem de estar em contato com as pessoas é mais forte do que a dimensão física que inibe o direito de ir e vir do aluno durante a aula.

Outra situação interessante ainda do momento do intervalo foi perceber como se dão algumas brincadeiras por parte dos alunos. Em seu diário Silva nos mostra que ao ir se

"afastando um pouco do refeitório atento minha atenção ao segundo pátio e logo me deparo mais uma vez com a fila indiana, só que agora para pularem corda. A brincadeira se dava com o auxílio de duas cuidadoras, cada uma numa ponta da corda e os meninos pulando um de cada vez. O interessante desse momento foi perceber que entre eles não há distinção ou mesmo restrição em relação a essa brincadeira para meninos ou meninas. Eles simplesmente brincam, pensando apenas em não errar o pulo e acabar perdendo a vez." (SILVA, 2017, p. 4). 
Visto isso, podemos compreender que embora esses alunos estejam em estado de recreação, é perceptível a partir desse diálogo que os mesmos permanecem sendo vigiados pelas "cuidadoras". É compreensível que as mesmas estejam naquela situação por também terem a função de cuidar para que o alunado não se machuque ou algo do tipo, no entanto, chamamos atenção aqui para a vigilância exercida pelas mesmas.

Existe todo um contexto sociocultural que funcionaliza essa postura das referidas; em muitos momentos os alunos tem brincadeiras mais agressivas - por carregarem culturalmente esse tipo de brincadeira. Então, ao reproduzirem isso entre os colegas, acaba por atrair, mesmo que involuntariamente a requisição dessa vigilância. Logo, não partilhamos dessa postura exercida para manter o equilíbrio entre as relações que os alunos constroem nesse momento do cotidiano escolar.

Destarte, a partir de agora buscaremos responder mais precisamente aos questionamentos postos nos objetivos desse trabalho e como aos que vieram a ser elencados no corpo do texto; a exemplo: como podemos perceber a apropriação dos corpos na educação básica atualmente? De que forma essa docilidade deixa lacunas no processo de ensinoaprendizagem? Qual o papel dos licenciandos diante dessa realidade?

\section{ESTADO DA ARTE}

Ao percebermos que existe uma inércia cultural no sistema escolar, baseado numa ideologia libertadora no qual idealiza a mobilidade social do indivíduo a partir de sua inserção no espaço escolar - compreendemos que existe uma série de mecanismos que compõem o sistema escolar e acabam por auxiliar a escola no processo de conservação de uma hierarquia social.

Desta maneira, compreendemos a partir de Bourdieu (1998, p. 42) que "a influência do cultural se deixa apreender sob a forma da relação, muitas vezes constatada, entre o nível cultural global da família [...]”. Assim, vemos nesse processo de vigilância dos corpos e modos que o alunado vem recebendo, mais uma maneira de - mesmo que indiretamente conservar a ideologia que permeias os espaços escolares, onde segrega os alunos a partir de suas práticas cotidianas e culturais. 
Logo, é essencial que nós, enquanto profissionais da educação, atentemo-nos para os métodos no qual fazemos uso para amparar nossos alunos. Tendo em vista que não devemos reforçar essas práticas ideológicas, mas combatê-las por meio de métodos mecanismos educacionais voltados para um processo humanizador contemplando a realidade dos alunos.

É necessário que percebamos o sujeito a partir do seu lugar social quando formos pensar as metodologias de ensino, pois, esse capital cultural carregado pelo aluno não é algo construído no seio escolar, mas a partir da transmissão de seus pares, no seu ciclo familiar e social.

Pensando sobre as relações entre os sujeitos escolares, devemos ressaltar sempre a importância de não tentarmos aculturar esses jovens com medidas de docilização dos sujeitos, mas percebê-los como pessoas que partem de lugares diferentes e por isso devem ser assistenciados de acordo com suas particularidades dentro das possibilidades que a escola pode subsidiar.

Assim sendo, é imprescindível entender que a posição social do aluno é um fator muitas vezes determinante quando pensamos as posturas escolares dos jovens, pois os mesmos estão ligados a uma rede de condições objetivas que podem não conceber assistência. De acordo com os relatos de Silva:

Por ser uma escola inserida numa zona social pobre de recursos financeiros, a mesma tende a enfrentar problemas com relação ao comportamento dos alunos. No entanto, é cabível ressaltar que a mesma tem tentado possibilitar um ensino de qualidade mesmo diante das deficiências financeiras e culturais que vem enfrentando, possibilitando aos alunos - a partir das condições da escola - um auxílio material e psicológico na construção do conhecimento. (SILVA, 2017, p. 2).

Portanto, ao pensarmos a escola e sua função que muitas vezes ainda é conservadora quando pensamos a partir de uma ótica generalizante - entendemos esses processos de docilidade dos corpos como um fomento para a sustentação da hierarquia aristocrática existente no espaço escolar. E, ao tentarmos pensar em ações que possam construir uma ideologia - a partir dos conteúdos e espaço - mais igualitária, é necessário que pensemos na democratização do acesso dos alunos aos mais diversos conhecimentos, descortinando suas 
experiências e entendendo-as dentro de seu contexto e importância social. Além de possibilitar a construção - por parte dos alunos - de espaços de protagonização.

\section{CONCLUSÕES}

Quando pensei em construir esse artigo, visava contribuir cientificamente com essa metodologia adotada no Estágio Supervisionado I, baseada na etnografia - não como método, mas como uma maneira de ter uma relação humanizadora entre o estagiário e os sujeitos escolares. Com isso, foi possível perceber que esse processo de docilidade dos corpos distancia os sujeitos escolares dessas relações que permeiam o processo de ensinoaprendizagem com um modo humanizado, ao reproduzirem a hierarquia sobre os jovens.

Portanto, concluímos esse artigo compreendendo que para os licenciandos está posto o desafio e desconstruir essa ideologia hierarquica ainda predominante no espaço escolar. E, com isso, devemos tomar como auxílio metodológico a sensibilização do nosso olhar enquanto educadores em formação frente as formas de protagonização simbólica que os jovens encontram para construírem seus espaços de atuação. Cabe a nós criarmos caminhos que envolvam os alunos nos processos de elaboração do conhecimento e que eles se percebam, dentro de suas realidades e cargas culturais, como sujeitos ativos - dentro e fora do espaço escolar. E não mais como pessoas que estão na escola só para aprender algo por que "a escola sabe o que é certo ou errado". 
REFERÊNCIAS BIBLIOGRÁFICAS

BOURDIEU, Pierre. A escola conservadora: as desigualdades frente à escola e à cultura. Escritos de educação, v. 8, p. 39-64, 1998.

FOUCAULT, Michel. Vigiar e Punir: nascimento da prisão. Trad. Raquel Ramalhete, 1977.

MOSÉ, Viviane. Palestra: O que a escola deveria aprender antes de ensinar? Proferida no programa Café filosófico CPFL, publicado no dia 13 de setembro, Brasil, 2013. Disponível em: https://www.youtube.com/watch?v=EigUj_d5n80.

SILVA, Maria L. E. da. Expedição Etnográfica. In. Diário de campo. Trabalho inspirado na disciplina de Estágio Supervisionado I, ministrada pela professora Ana Rita Uhle no curso de Graduação em História, UFCG/CFP. Cajazeiras-PB, 2017. Mimeo. 
